УДК 663.1; 663.5

\title{
DYNAMICS OF TRANSITION PROCESSES IN SYSTEMS OF ANAEROBIC FERMENTATION
}

\author{
O. Shevchenko, A. Sokolenko, O. Stepanets, O. Boiko, I. Vinnichenko \\ National University of Food Technologies
}

\begin{tabular}{|c|c|}
\hline Key words: & ABSTRACT \\
\hline $\begin{array}{l}\text { Anaerobic fermentation } \\
\text { Solubility } \\
\text { Saturation } \\
\text { Gas phase } \\
\text { Mass transfer } \\
\text { Gas-liquid medium } \\
\text { potential } \\
\text { Altitude gradient }\end{array}$ & $\begin{array}{l}\text { The article presents the results of the phenomenological } \\
\text { analysis of the flow of aggregate processes under conditions } \\
\text { of anaerobic fermentation, examines the differences that } \\
\text { accompany them in the brewing and alcohol industries. The } \\
\text { estimation of energy potentials is carried out, recommen- } \\
\text { dations of their use are offered. Firstly,it is formulated the } \\
\text { position on the formation of the gas-liquid medium formed } \\
\text { as a result of synthesis of } \mathrm{CO}_{2} \text { and the formation of a }\end{array}$ \\
\hline $\begin{array}{l}\quad \text { Article history: } \\
\text { Received } 06.11 .2017 \\
\text { Received in revised form } \\
27.11 .2017 \\
\text { Accepted } 14.12 .2017\end{array}$ & $\begin{array}{l}\text { dispersed gas phase. It is indicated on the existence of the } \\
\text { high-altitude gradient for saturation of the liquid phase on } \\
\mathrm{CO}_{2} \text { because of the expense of hydrostatic pressure. The } \\
\text { estimated data are also provided. }\end{array}$ \\
\hline $\begin{array}{l}\text { Corresponding author: } \\
\text { O. Shevchenko } \\
\text { E-mail: } \\
\text { npnuht@ukr.net }\end{array}$ & \\
\hline
\end{tabular}

DOI: $10.24263 / 2225-2924-2017-23-6-10$

\section{ДИНАМІКА ПЕРЕХІДНИХ ПРОЦЕСІВ У СИСТЕМАХ АНАЕРОБНОГО БРОДІННЯ}

\author{
О.Ю. Шевченко, А.І. Соколенко, О.І. Степанець, О.О. Бойко, І.М. Вінніченко \\ Національний університет харчових технологій
}

У статті викладено результати феноменологічного аналізу перебігу сукупності процесів в умовах анаеробного бродіння, розглянуто відмінності, щзо супроводжують їх у пивоварінні і спиртовій галузях. Виконано оцінку енергетичних потенціалів, запропоновано рекомендації щзодо їх використання. Вперше сформульовано положення про формування потенціалу газорідинного середовища, щз виникає в результаті синтезу $\mathrm{CO}_{2}$ i утворення диспергованої газової фази, а також вказано на існування висотного градієнта по насиченню рідинної фази на $\mathrm{CO}_{2}$ за рахунок гідростатичного тиску. Наведено відповідні розрахункові дані.

Ключові слова: анаеробне бродіння, розчинність, насичення, газова фаза, масообмін, потенціал газорідинного середовища, висотний градієнт. 
Постановка проблеми. Зазвичай, до перехідних процесів анаеробного i аеробного бродіння відносяться режими лаг-фази і доброджування, які характеризуються обмеженими проявами життєдіяльності дріжджових культур. Лаг-фаза обумовлюється необхідністю адаптації дріжджів-цукроміцетів до нових умов середовища 3 подоланням осмотичних, температурних і хімічних шоків, а режим доброджування пов'язується 3 низькою концентрацією живильних речовин і осмотичними тисками. Останне у більшості випадків стосується етилового спирту і діоксиду вуглецю, динаміка накопичень яких пов'язана з алгоритмами основного етапу бродіння.

До числа недоліків анаеробного бродіння відносяться обмежена кінцева концентрація етилового спирту на рівні $8 . . .10 \%$ і матеріальний баланс біохімічного процесу, за яким близько $50 \%$ глюкози як живильного середовища перетворюється в діоксид вуглецю. Ці головні і незмінні недоліки супроводжуються трьома похідними від них, що стосуються необхідності використання значних об'ємів культуральних середовищ, синтезу біологічної теплоти бродіння, значних енерговитрат на перегонку.

Численні зусилля мікробіологів у напрямку створення осмофільних дріжджів-цукроміцетів залишаються нереалізованими, за винятком обмежених успіхів у технологіях вторинного зброджування виноматеріалів 3 досягненням 12-відсоткової концентрації $\mathrm{C}_{2} \mathrm{H}_{5} \mathrm{OH}$ [1-3]. Однак у виробництві шампанського технологічною особливістю $є$ необхідність одержання концентрації $\mathrm{CO}_{2}$ на рівні 10 г/л, тоді як вміст етилового спирту корегується додаванням у шампанізований матеріал коньячного спирту.

У пивоварній галузі проблеми накопичення етилу і діоксиду вуглецю практично подолані, тоді як виробництво етилового спирту потребує втручань хоча б на рівні вказаних похідних недоліків. Розв'язання таких завдань доцільно здійснювати в напрямку використання внутрішніх енергетичних потенціалів газорідинних середовищ.

Метою статті $\epsilon$ аналіз і оцінка енергетичних потенціалів культуральних середовищ у процесах анаеробного бродіння та розробка рекомендацій щодо реалізації їх використання.

Методика дослідження передбачає поглиблений аналіз гідродинамічного стану газорідинних культуральних середовищ на основі положень гідромеханіки і термодинаміки.

Викладення основних результатів дослідження. До внутрішніх енергетичних потенціалів зброджуваних культуральних середовищ відносяться:

- потенціальна енергія набухлого шару за рахунок газоутримувальної здатності;

- потенціальна енергія газового надрідинного об'єму;

- кінетична енергія самоплинних або організованих циркуляційних контурів;

- потенціал середовища за градієнтом насичення середовища по гідростатичному тиску;

- біологічна теплота ендогенного синтезу спирту і діоксиду вуглецю;

- робота розширення диспергованої газової фази. 
Названі потенціали наявні в газорідинних середовищах і мають прояви в самоплинних процесах, рушійні фактори яких у більшості пов'язані 3 утворенням диспергованої газової фази. Першопричиною їх появи $є$ синтез діоксиду вуглецю (закон Гей-Люссака) 3 подальшим переліком процесів масообміну на границі поділу фаз, насичення ним рідинної фази (закон Генрі), утворення диспергованої газової фази, прояви законів Архімеда і Стокса 3 утворенням динамічної газоутримувальної здатності. відповідальної за потенціальну енергію набухлого шару і кінетичну енергію циркуляційних контурів.

Утворення потенціалу середовища по градієнту насичення рідинної фази діоксидом вуглецю пояснюється законами Генрі і гідростатичного тиску. Однак наявність такого градієнта в умовах самоплинного хаотичного процесу за існування циркуляційних контурів помітно обмежує прояв його потенціалу.

3 наведеного переліку енергетичних потенціалів зброджуваних середовищ лише біологічна теплота синтезу $\mathrm{C}_{2} \mathrm{H}_{5} \mathrm{OH}$ і $\mathrm{CO}_{2}$ зовнішньо випадає із загальної сукупності взаємодій інших енергетичних потенціалів, хоча вона $\epsilon$ логічним супроводом останніх. Самоплинність названих процесів енергетичною основою має хімічну енергію неперервного розпаду і трансформації цукрів у спирт і діоксид вуглецю.
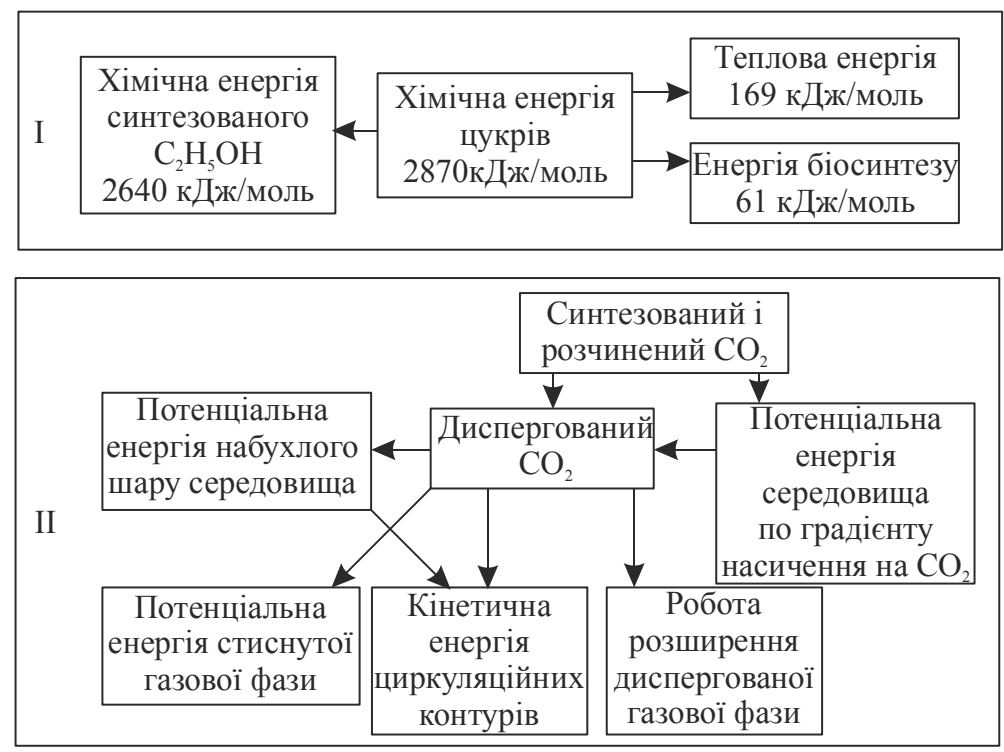

Рис. 1. Структура енергетичних потенціалів зброджуваних середовищ

На рис. 1 схематично показана структура енергетичних потенціалів, що складається 3 двох блоків, перший $з$ яких представлений хімічною енергією розчинених цукрів 3 балансом хімічної енергії синтезованих $\mathrm{C}_{2} \mathrm{H}_{5} \mathrm{OH}$ i енергії біохімічного синтезу. Вказані тут співвідношення є загальновизнаними $[1 ; 3 ; 4]$ і супроводжуються кількісними показниками, тоді як блок II сформовано на основі феноменологічних висновків. Його першопричиною прийнято вважати синтезований і розчинений діоксид вуглецю, енергетич- 
ний потенціал якого не має проявів від початку зброджування середовищ до досягнення стану насичення. Рушійний градієнт у зростанні концентрації розчиненого $\mathrm{CO}_{2}$ стосується двох факторів - атмосферного тиску та прояву гравітаційного поля у формі гідростатичного тиску, і визначається різницею граничного насичення рідинної фази на $\mathrm{CO}_{2}$ і плинного значення цього показника.

За сучасними уявленнями, зброджувальні властивості дріжджів-цукроміцетів помітно обмежено реагують на збільшення фізичних тисків і на цій підставі можливо припустити існування рівномірності процесу бродіння у повному об'ємі технологічного апарата. При цьому видно (табл.), що стала насичення середовища на $\mathrm{CO}_{2}$ помітно залежить від гідростатичного тиску, що визначає існування висотного градієнта за показником $c_{\mathrm{H}}$.

Таблиия. Залежність граничної насиченості рідинної фази на $\mathrm{CO}_{2}$ від гідростатичного тиску середовища при зовнішньому тиску 0,1 МПа і температурі $30^{\circ} \mathrm{C}$

\begin{tabular}{|c|c|c|c|c|c|c|c|c|c|c|c|}
\hline $\begin{array}{c}\text { Гранична } \\
\text { насиченість, кг/м }\end{array}$ & 1,554 & 1,628 & 1,776 & 1,924 & 2,072 & 2,220 & 2,368 & 2,516 & 2,664 & 2,812 & 2,960 \\
\hline $\begin{array}{c}\text { Гідростатичний } \\
\text { тиску рідинної } \\
\text { фази, м в. ст. }\end{array}$ & 0,5 & 1 & 2 & 3 & 4 & 5 & 6 & 7 & 8 & 9 & 10 \\
\hline
\end{tabular}

Прояви дії названих енергетичних потенціалів починаються від моментів досягнення стану насичення й утворення диспергованої газової фази. Остання під дією архімедових сил починає спливання, відбувається набухання газорідинного середовища. Поступово утворення диспергованої газової фази продовжується в напрямку заглиблення, що завершується газоутворенням у повному об'ємі.

На рис. 2 наведена графічна інтерпретація залежності граничної розчин-

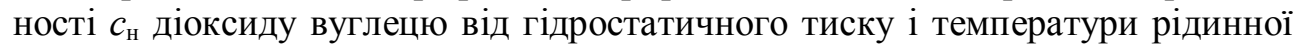
фази середовища. Аналізуючи графіки, можна зробити висновок про перспективи використання градієнтів насиченості середовищ для інтенсифікації процесів масообміну в напрямках організованих циркуляційних контурів і режимах зміни температур.

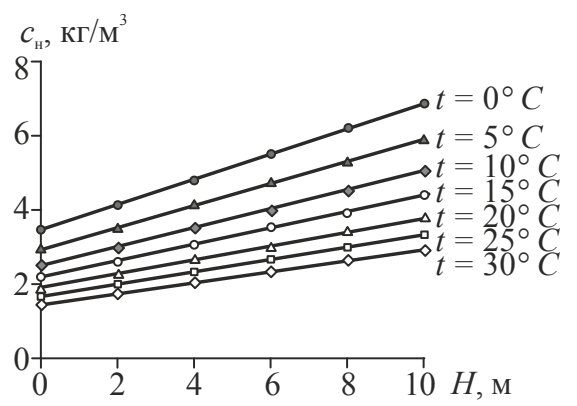

Рис. 2. Залежність сталої насичення на $\mathrm{CO}_{2}$ середовища від висоти рідинного шару при сталій швидкості бродіння і зовнішньому тиску 0,1 МПа 
Динаміка насичення середовища пов'язана зі швидкістю зброджування цукрів $d G_{\text {ц }} / d \tau$ i, відповідно, зі швидкістю синтезу $\mathrm{CO}_{2}$ у формі:

$$
\frac{d G_{\mathrm{CO}_{2}}}{d \tau}=\frac{d G_{\text {щ }}}{d \tau} \cdot \frac{2 \cdot 44}{180}=0,48 \frac{d G_{\text {щ }}}{d \tau},
$$

де $d G_{\mathrm{CO}_{2}}$ i $d G_{\text {ц }}$ - відповідно. концентрації цукрів і діоксиду вуглецю в режимі бродіння і насичення середовища; 180 і $44-$ молекулярні маси глюкози і діоксиду вуглецю; $\tau$ - час перебігу процесу.

За умов $d G_{\text {ц }} / d \tau=$ const $\mathrm{i} d G_{\mathrm{CO}_{2}} / d \tau=$ const можливим $\epsilon$ визначення часу насичення на різних глибинах Н рідинного середовища:

$$
\tau_{(\mathrm{\kappa})}=\frac{c_{\mathrm{H}}(H)}{0,489 \frac{d G_{\mathrm{u}}}{d \tau}} .
$$

За первинної концентрації цукрів 160 кг/м³ і подовженням часу бродіння до 72 год середня швидкість процесу складає:

$$
\frac{d G_{\text {แ }}}{d \tau}=\frac{G_{\text {щ }}}{\tau}=\frac{160}{3600 \cdot 72}=0,00062 \mathrm{\kappa г} /\left(\mathrm{M}^{3} \cdot \mathrm{c}\right) .
$$

Відповідно, отримуємо:

$$
\frac{d G_{\mathrm{CO}_{2}}}{d \tau} 0,489 \cdot 0,00062=0,000303 \kappa \Gamma /\left(\mathrm{M}^{3} \cdot \mathrm{c}\right) .
$$

Оскільки для значень Н від 1 до 10 м граничні значення с н складають 1,628 і 2,96 кг $/ \mathrm{m}^{3}$, то кінцевий час насичення досягається за:

$$
\begin{gathered}
\tau_{(\kappa) 1}=\frac{1,628}{0,489 \cdot 0,00062}=5369,7, c=1,49 \text { год; } \\
\tau_{(\mathrm{\kappa}) 10}=\frac{2,69}{0,489 \cdot 0,00062}=88,73, c=2,46 \text { год. }
\end{gathered}
$$

Існування градієнта насичення в діапазоні значень $H=1$ м і $H=10$ м розпочинається від моменту досягнення $\tau_{(\kappa) 1}$ в зростаючому варіанті до $\tau_{(\kappa) 10}$. У загальному випадку висотний градієнт визначається залежністю:

$$
\operatorname{grad} c_{\mathrm{H}}=\frac{\Delta c_{\mathrm{H}}}{\Delta H} .
$$

Відповідно, за умови температури середовища $30^{\circ} \mathrm{C}$ отримуємо:

$$
\operatorname{grad} c_{\mathrm{H} 30^{\circ} \mathrm{C}}=\frac{c_{\mathrm{H} 10}-c_{\mathrm{H} 1}}{10-1}=\frac{2,96-1,68}{9}=0,148 \frac{\kappa \Gamma}{\mathrm{M}^{3}} / \mathrm{M},
$$

а при $t=0^{\circ} \mathrm{C}$ градієнт зростає до значення:

$$
\operatorname{grad} c_{\mathrm{H} 0^{\circ} \mathrm{C}}=\frac{6,886-3,784}{9}=0,344 \frac{\mathrm{\kappa} \Gamma}{\mathrm{M}^{3}} / \mathrm{M} .
$$


Розраховані значення градієнтів повної висоти рідинної фази від нуля до 10 м складають за значень таких температур:

$$
\begin{gathered}
t=0^{\circ} \mathrm{C} \operatorname{grad} c_{\mathrm{H} 0^{\circ} \mathrm{C}}=0,344 \frac{\mathrm{K \Gamma}}{\mathrm{M}^{3}} / \mathrm{M} ; t=15^{\circ} \mathrm{C} \operatorname{grad} c_{\mathrm{H} 15^{\circ} \mathrm{C}}=0,219 \frac{\mathrm{K} \Gamma}{\mathrm{M}^{3}} / \mathrm{M} ; \\
t=5^{\circ} \mathrm{C} \operatorname{grad} c_{\mathrm{H} 5^{\circ} \mathrm{C}}=0,294 \frac{\mathrm{K \Gamma}}{\mathrm{M}^{3}} / \mathrm{M} ; t=20^{\circ} \mathrm{C} \operatorname{grad} c_{\mathrm{H} 20^{\circ} \mathrm{C}}=0,191 \frac{\mathrm{K} \Gamma}{\mathrm{M}^{3}} / \mathrm{M} ; \\
t=10^{\circ} \mathrm{C} \operatorname{grad} c_{\mathrm{H} 10^{\circ} \mathrm{C}}=0,252 \frac{\mathrm{K \Gamma}}{\mathrm{M}^{3}} / \mathrm{M} ; t=25^{\circ} \mathrm{C} \operatorname{grad} c_{\mathrm{H} 25^{\circ} \mathrm{C}}=0,167 \frac{\mathrm{K \Gamma}}{\mathrm{M}^{3}} / \mathrm{M} .
\end{gathered}
$$

Наведені співвідношення та їх графічна інтерпретація (рис. 3) вказують на зростання градієнта зі зниженням температури, що за інших рівних умов відповідає фізичній суті закону Генрі.

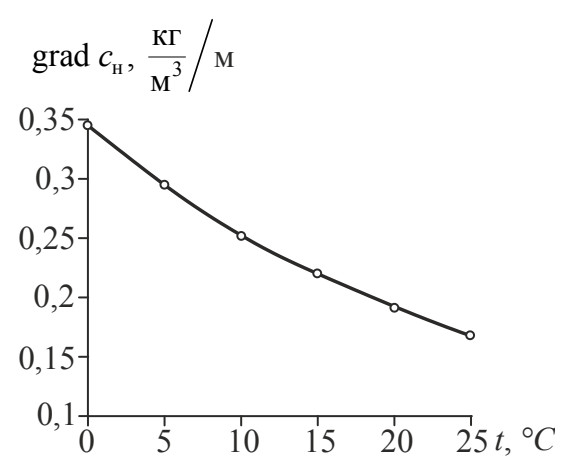

Рис. 3. Графік залежності градіснта насиченості від температури середовища

Це одночасно означає зростання енергетичного потенціалу газонасиченого середовища, у тому числі при перебуванні його в стані статичної рівноваги. Прояв такого потенціалу з трансформацією в потенціальну і кінетичну енергію можливий лише за зовнішнього збурення у формі зниження тиску або підвищення температури. Очевидно, що перший з них технічно легко реалізується, тоді як другий є значно інертнішим у реалізації.

За перебігу звичайного процесу бродіння від досягнення граничного насичення середовища в повному об'ємі починається активна фаза виведення $\mathrm{CO}_{2}$ у кількості масового потоку, що відповідає його синтезу:

$$
\frac{d G_{\mathrm{CO}_{2}}^{\prime}}{d \tau}=0,489 \frac{d G_{\text {ц }}}{d \tau} V_{\text {p.ф. }} \text { Кг } / \mathrm{c},
$$

де $V_{\text {р.ф. }}$ - об'єм рідинної фази в апараті, м².

Об’ємний потік на межі поділу газорідинного середовища і надрідинної газової фази становить:

$$
V_{\mathrm{CO}_{2}}=\frac{d G_{\mathrm{CO}_{2}}^{\prime}}{d \tau} / \rho \mathrm{m}^{3} / \mathrm{c}
$$

де $\rho$ - питома маса $\mathrm{CO}_{2}, \kappa г / \mathrm{M}^{3}$. 
Об'ємний газовий потік $V_{\mathrm{CO}_{2}}$ дає змогу оцінити приведену швидкість газової фази:

$$
w_{\mathrm{CO}_{2}}=\frac{V_{\mathrm{CO}_{2}}}{F}=\frac{d G^{\prime}}{d \tau} /(F \rho) \mathrm{M} / \mathrm{c},
$$

де $F$ - площа поперечного перерізу бродильного апарата.

У більшості технологій, пов'язаних із взаємодією газових і рідинних фаз, із завданнями сорбції або десорбції саме показник приведеної швидкості використовується для моделювання гідродинамічних режимів і повноцінних характеристик процесів [5; 6]. Практично він нівелює вплив геометричних параметрів апаратів аеробного й анаеробного синтезу, хімічних реакторів, десорберів тощо за рахунок введення у формулу (12) площі поперечного перерізу апарата.

Важливим доповненням до приведеної швидкості газової фази в оцінках гідродинамічного стану газорідинних середовищ $\epsilon$ їх газоутримувальна здатність. Оскільки остання є об'ємом газової фази, що одномоментно знаходиться в середовищі, то це означає, що вона визначає величини поверхні та інтенсивність масопередачі, потенціальну енергію набухання газорідинної суміші та кінетичну енергію циркуляційних контурів. За відомого об'ємного потоку $V_{\mathrm{CO}_{2}}$, що синтезується в середовищі, газоутримувальна здатність визначається залежністю:

$$
u=V_{\mathrm{CO}_{2}} \frac{H^{\prime}}{w_{\text {сплив. }}} \mathrm{m}^{3},
$$

де $w_{\text {сплив. }}-$ абсолютна швидкість спливання диспергованої газової фази, м/с; $H^{\prime}$ — повна висота середовища.

Вказана швидкість $w_{\text {сплив. }} \epsilon$ сумою відносної швидкості $w_{\text {відн. }}$ яка регламентується рівністю архімедових сил і сил опору середовища, та швидкістю $w_{\text {ц.к. }}$ винесення газової фази в циркуляційних контурах:

$$
w_{\text {сплив. }}=w_{\text {відн. }}+w_{\text {ц.к. }} .
$$

Для рідинних середовищ із фізико-хімічними характеристиками близькими до води значення $w_{\text {відн. }}$ наближені до показників $0,23 \ldots 0,25 \mathrm{~m} / \mathrm{c}$, тоді як абсолютні швидкості спливання помітно залежать від величин газових потоків i, наприклад, у режимах примусової аерації досягають значень 0,5 ..0,6 м/с.

Наведене рівняння (14) в сукупності з умовою (13) і на основі експери-

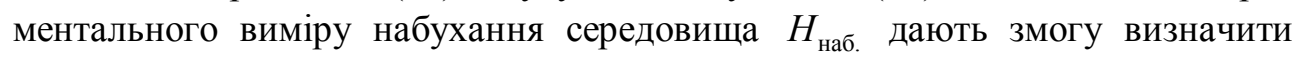
$w_{\text {ц.к. }}$ У такій послідовності:

$$
u=H_{\text {наб. }} F ; w_{\text {сплив. }}=V_{\mathrm{CO}_{2}} \frac{H^{\prime}}{u}=\frac{V_{\mathrm{CO}_{2}} H^{\prime}}{H_{\text {наб. }} F} ; w_{\text {ц.к. }}=\frac{V_{\mathrm{CO}_{2}} H^{\prime}}{H_{\text {наб. }} F}-w_{\text {відн. }} .
$$

Одержане значення $w_{\text {ц.к. }}$ надає можливість у першому наближенні визначити кінетичну енергію циркуляційних контурів на основі припущення про участь в них маси всієї рідинної фази $m_{\mathrm{p}}$ : 


$$
E_{\text {кін. }}=m_{\mathrm{p}} \frac{w_{\mathrm{L}, \mathrm{\kappa} .}^{2}}{2}=\frac{m_{\mathrm{p}}}{2}\left(\frac{V_{\mathrm{CO}_{2}} H^{\prime}}{H_{\text {нао. }} F}-w_{\text {відн. }}\right) .
$$

3 останньої умови видно узагальнену оцінку впливу геометричних параметрів середовища й апарата. Збільшення висоти шару середовища $H^{\prime}$ приводить до зростання кінетичної енергії системи, тоді як збільшена площа $F$ поперечного перерізу в ізооб'ємних апаратах призводить до зменшення потенціалу кінетичної енергії.

Значення $E_{\text {кін. }} \in$ керованим параметром, потужний прояв якого пов'язаний 3 швидкоплинним імпульсним зниженням тиску в газовому надрідинному об'ємі. Реакція системи при цьому проявляється у формі десатураційного виділення газової фази з кожного кубічного метра середовища у кількості:

$$
\Delta c=k\left(p_{(\text {п) }}-p_{(\kappa)}\right) \kappa \Gamma / \mathbf{M}^{3},
$$

де $p_{(\text {п) }}$ і $p_{(\text {к) }}$ - відповідно, початковий і кінцевий тиски газової фази в надрідинному об'ємі, бар; $k$ - константа Генрі, кг/(м³.бар).

Повне виділення газової фази в цьому перехідному процесі становить:

$$
\Delta c^{\prime}=k\left(p_{(\text {п) }}-p_{(\text {к) }}\right) V_{\text {рід. }} \text { кг, }
$$

де $V_{\text {рід. }}$ - об'єм рідинної фази, м³

Очевидно, що в такому процесі показники умов (15) і (16) будуть значно перевищені порівняно з усталеними режимами, однак і при цьому рідинна фаза залишається в стані граничного насичення на $\mathrm{CO}_{2}$. Для ліквідації останнього недоліку має місце лише один варіант у формі швидкоплинного підвищення тиску газової фази в надрідинному об'ємі, за якого різко зростає показник граничного насичення $c_{\text {н }}$ відповідно до закону Генрі.

$\mathrm{У}$ циркуляційних контурах наявний самоплинний процес десатурації $\mathrm{i}$ подальшого насичення середовища в послідовних переміщеннях газорідинного середовища у висхідній, а потім в опускній частинах контурів. Однак доцільно відмовитися від самоплинності в таких процесах і перейти до організованої циркуляції по всій висоті середовища [7]. В цьому випадку реалізується потенціал висотного градієнта 3 додатковою функцією корегування $\mathrm{i}$ вирівнювання температурного поля, що особливо важливо у випадках сорочкових систем охолодження циліндро-конічних бродильних апаратів. Трансформація глюкози в спирт в режимі анаеробного бродіння супроводжується різницею вільної енергії Гіббса:

$$
\Delta G=2870-2640=230 \text { кДж/моль глюкози, }
$$

а залишок у кількості 169 кДж/моль трансформується в теплоту. При циклічному зброджуванні в кожному кубічному метрі середовища зі 160 кг глюкози кількість біологічної теплоти повинна скласти близько 150220 кДж. Цієї теплової енергії за теплоти пароутворення спирту $r_{\text {сп. }}=910,9$ кДж/кг вистачає для відгонки 165 кг, що майже вдвічі перевищує питомий вихід спирту при бродінні. 
Однак сучасні технології перегонки потребують трансформації низькопотенціальної теплоти у високопотенціальну, наприклад, за рахунок використання теплових насосів.

\section{Висновки}

Виконаний аналіз особливостей перебігу процесів анаеробного зброджування цукровмісних середовищ, масообмінних, гідродинамічних і термодинамічних процесів дає змогу зробити такі висновки:

1. Зброджувані середовища характеризуються двома енергетичними джерелами. Першопочатковим з них є хімічна енергія цукрів, яка підлягає мікробіологічним трансформаціям 3 визначеними співвідношеннями у формі вільної енергії Гіббса і теплоти переходу від АТФ до АДФ.

2. Залишок теплової енергії у кількості 169 кДж/моль глюкози частково бере участь у створенні циркуляційних газорідинних контурів.

3. Синтез діоксиду вуглецю дріжджовими клітинами і створення диспергованої газової фази в рідинній у гравітаційному полі у формі гідростатичних тисків, законів Архімеда і Генрі створює джерело механічної енергії в проявах потенціальної і кінетичної енергій. Це надає можливість:

- інтенсифікувати масообмінні процеси, забезпечувати зміни десатураційних явищ зі зниженням осмотичних тисків і відновленням сатураційних властивостей середовища за рахунок змінних програмованих тисків з витримкою в часі пауз на десатурацію (знижений тиск) і активовану сатурацію (підвищений тиск);

- забезпечувати організовану повноглибинну циркуляцію для використання потенціалу градієнта висотного насичення середовища на $\mathrm{CO}_{2}$;

- використовувати трансформовану біологічну теплоту бродіння для перегонки.

\section{Література}

1. Куние B. Технология солода и пива / В. Кунце. - Санкт-Петербург : Профессия, 2001. $-912 \mathrm{c}$.

2. Лензіон C.B. Розвиток методів розрахунку і обладнання транспортно-технологічних систем у виробництві шампанських вин : дис. ... канд. техн. наук : 05.18.12 / Лензіон Сергій Валентинович ; НУХТ. — Київ, 2011. — 139 с.

3. Шиян П.Л. Інноваційні технології спиртової промисловості. Теорія і практика : монографія / П.Л. Шиян, В.В. Сосницький, С.Т. Олійничук. —Київ : ВД Асканія, 2009. — 424 с.

4. Соколенко A.I. Особливості трансформацій енергоматеріальних потоків у замкнутих енергетичних контурах / А. І. Соколенко, В. А. Піддубний, О. В. Коваль // Наукові праці Національного університету харчових технологій. — 2017. — Т. 23. — № 3. — С. 101-106.

5. Палаш A.A. Розвиток теоретичного підгрунтя і удосконалення обладнання для культивування мікроорганізмів : автореф. дис. ... канд. техн. наук : 05.18 .12 «Процеси та обладнання харчових, мікробіологічних та фармацевтичних виробництв» / Палаш Анатолій Анатолійович ; НУХТ. - Київ, 2009. - 20 с.

6. Шевченко О.Ю. Особливості трансформацій матеріальних і енергетичних потоків у бродильних середовищах / О.Ю. Шевченко, І.М. Вінніченко, О.І. Степанець, О.О. Бойко // Наукові праці Національного університету харчових технологій. — 2017. — Т. 23. — № 3. C. $107-115$.

7. Патент 47939 UA, MПК C12F 3/08 (2006.01) Бродильний апарат / Соколенко А.I., Шевченко О.Ю., Миколів І.М., Буг С.А., Піддубний В.А., Лензіон С.В. ; заявник Національний університет харчових технологій. — № u200910298 ; заявл. 12.10.2009 ; опубл. 25.02.2010, Бюл. № 4, 2010 p.

8. Патент 75184 UA, MПК C12F 3/08 (2006.01) Бродильний апарат / Чагайда A.O., Піддубний В.А., Соколенко А.І. ; заявник Національний університет харчових технологій. № u201205226 ; заявл. 27.04.2012 ; опубл. 26.11.2012, Бюл. № 22, 2012 p. 